\title{
Ni-Cr-Mo Alloy for Dental Prostheses with Low Melting Temperature
} ALI Haider ${ }^{\mathrm{a},{ }^{*}}$, OMAR Farooq Azam ${ }^{\mathrm{b}}$, MUHAMMAD Talha ${ }^{\mathrm{c}}$, SALEEM Akhtar ${ }^{\mathrm{d}}$

\author{
Ibn-e-Sina Institute of Technology, Islamabad, Pakistan \\ aaalihyder@hotmail.com, bengromar.81@gmail.com, 'talhaadhamy@hotmail.com, \\ dengr_sakhtar@yahoo.com
}

Keywords: Ni-Cr-Mo, Dental Casting Alloy, Fusion Point, Castability, Dental Restoration.

\begin{abstract}
Ni-Cr alloys are popular for dental prostheses for the reason of economy and few better characteristics in comparison to expensive gold based alloys. However, alloy developed locally has higher melting temperature around $1400{ }^{\circ} \mathrm{C}$ as compared to that of proprietary alloys. The Ni-Cr alloys contain major alloying elements in following range: $50-80 \% \mathrm{Ni}, 10-30 \% \mathrm{Cr}, 3-10 \% \mathrm{Mo}$. Minor addition is made to have requisite properties suitable for dental prostheses. In this work investigation was carried out to find out optimum chemistry to have melting temperature of the alloy in the range of $1100-1200{ }^{\circ} \mathrm{C}$ without compromising the requisite mechanical and corrosion properties. Developed alloy was characterized using Scanning Electron Microscope, XRF, Inductive Coupled Spark Plasma, Vickers Hardness Tester and Differential Scanning Calorimetry. Results were analyzed and acceptable samples tested at dental laboratories for trial use and suitability for dental prostheses.
\end{abstract}

\section{Introduction}

Restoration of damaged or diseased dentals has been one of major concerns of health care since centuries. Selection of a metal or an alloy for dental reconstruction depends upon its characteristics including; biocompatibility, resistance to oxidation, tarnishing and corrosion, strength and hardness, ability to bond with porcelain and ease of fabrication or casting to the desired crown or bridge shapes. A variety of metals and alloys are in use for dental prostheses, however, each with its own merits and demerits.

Use of gold for dental restoration and bracing has history of around 4000 years. There have been many alternatives for gold but still gold has its own characteristics for dental restoration; being inert, ductile, corrosion and tarnishing resistant, long life, biocompatible and easy to manufacture to desired complex shapes. Worldwide consumption of gold for dental prostheses and restoration is around 70 metric tons [1]. As gold is expensive metal, other alternative alloys have been developed for the purpose of dental restoration.

New alloys are developed to replace gold as they have advantages like low price and lower density. Density of Ni-based alloys is around $9 \mathrm{~g} / \mathrm{cm}^{3}$ in comparison to that for gold which is $19.3 \mathrm{~g} / \mathrm{cm}^{3}$. Low density is useful property for making bulky dental prostheses [2]. Also Nickel based alloys possess better mechanical strength required for the prostheses.

Metals when come in contact with sweat or other human body fluids, corrosion process occurs. An anodic reaction occurs at the surface of metal where metal ions and free electrons are formed. This electrolytic reaction exerts toxic effect. However, some metals like chromium form continuous and adherent oxide film on the surface of their alloys and thus protect them against corrosion even in human fluids. Beryllium metal also has similar effect, it helps to increase corrosion resistance of the dental alloys [3]. Chromium metal is an important ingredient in Ni-alloys from view point of corrosion and tarnishing resistance. Studies [4] have shown that corrosion resistance of Ni-Cr dental alloys depend upon chromium content of the alloy. Chromium content more than 25 percent is found to produce corrosion resistant alloy, suitable for dental prostheses.

Porojan Liliana et al. reported that chromium content more than 20 percent is critical to have compact layer of $\mathrm{Cr}_{2} \mathrm{O}_{3}$ oxide on the surface of alloy [5]. If the chromium content is less than that critical value, the oxide formed is in loose stacks, which do not provide requisite corrosion resistance. 
Nickel-Chromium based alloys have become pertinent materials to select for dental restorations by virtue of their metallurgical, physical, aesthetic and economical properties. These alloys are more appreciated in developing nations for cost factor. Beryllium metal is added to Ni-Cr alloys to improve properties like hardness and reduce fusion temperature [6]. Although Beryllium has metallurgical qualities for alloy development and for improved mechanical strength, however, it has potential carcinogenic hazard if beryllium gas inhaled during melting, alloy processing and finishing stages [7].

Paulo Bartolo et al. has explained the importance for better and affordable health care for aging population and high expectations for better quality of life [8]. With age and due to mouth diseases, damaged dentals need repair or replacement. Loss of dentals due to diseases is a common and costly problem. Affordable and cheaper dental prosthesis is the requirement in developing and poor nations. Being affordable, Ni-Cr alloy has become commonly used alloy in dental restorations. In addition to cost benefit, while comparing with gold alloys, the $\mathrm{Ni}-\mathrm{Cr}$ alloy has another advantage as it is of indistinguishable color [9]. Ni-Cr alloy is, therefore, popular in dental restoration.

Added benefits of Ni-Cr alloys over other candidate materials for dental prosthesis include; better bond strength between the alloy and resins, due to high modulus of elasticity, stiffness of Ni$\mathrm{Cr}$ alloys is better than most of the dental alloys, thereby, thinner sections provide equivalent strength and long bridge making is possible [6]. Melting temperature of Ni-Cr-Mo dental alloy is in the range of $1360-1410{ }^{\circ} \mathrm{C}$. Ni-Cr based dental alloy contain minor additions of other elements for improvement in properties. Aluminum and titanium may be added to increase strength by formation of $\mathrm{Ni}_{3} \mathrm{Al}$ or $\mathrm{Ti}_{3} \mathrm{Al}$ precipitates. Molybdenum added to effect thermal coefficient of expansion. Tungsten and vanadium increase strength and harness of the alloy by solid solution strengthening mechanism [10].

Minor addition of beryllium helps to improve castability and porcelain bonding of Ni-Cr alloy [11]. Beryllium with nickel forms eutectic Ni-Be phase in the alloy [12]. Melting temperature of the $\mathrm{Ni}-\mathrm{Be}$ eutectic is around $1150^{\circ} \mathrm{C}$ [13]. The eutectic phase melts first during melting process and helps to improve fluidity of the molten alloy, and therefore improved castability $[12,14]$. Better castability of $\mathrm{Ni}-\mathrm{Cr}$ alloys is achieved at $1340^{\circ} \mathrm{C}$ [2]. Poor castability affects the complete filling of dental crown margins during melting and casting process. Castability is an important factor while manufacturing crowns, as crown must fit the teeth and better castability means better fitting of crowns and prepared teeth [15-18] Beryllium is known to decrease melting point of Ni-based alloy and improve bond strength with porcelain [19].

Ni-based dental alloys are usually classified as Be-free or Be-containing alloys. Alloying with Beryllium improves castability as it lowers melting temperature of the alloy to around $1100^{\circ} \mathrm{C}$ [20]. Beryllium addition also increases hardness of the NiCrMo alloy as it forms Ni-Be eutectic phase in the structure.

If melting temperature of Ni-Cr dental alloy is higher, it is usually not appreciated by dental laboratory technicians. High melting point needs higher power of the furnace and more energy and more time required for melting and casting. While melting and casting at higher temperatures, the quantity of absorbed gases in the molten alloy increases which increase inclusion index and impurities in the alloy and thereby causing brittleness in the alloy. Recycling of the alloy also becomes almost impossible. When the alloy is in molten state, it has high ability to absorb atmosphere gases like hydrogen, oxygen, nitrogen and carbon that make the alloy brittle [19].

This work was undertaken to study systematically the phenomenon of fusion of $\mathrm{Ni}-\mathrm{Cr}$ alloys and find out most suitable composition with melting temperature in the range of $1100-1200{ }^{\circ} \mathrm{C}$; to make the alloy easy for casting and fabrication for dental prostheses.

\section{Experimental Work}

Pure elements of $\mathrm{Ni}, \mathrm{Cr}, \mathrm{Mo}, \mathrm{Al}, \mathrm{Ti}, \mathrm{Si}$ and Be with purity of $99.99 \%$ used for alloy development to exclude effects of any undesired elements. Alloys prepared of aimed composition at vacuum induction melting furnace using Argon as inert gas for flushing and pressures during 
melting. Vacuum level of $10^{-5}$ mbar used to exclude any chance of oxidation of alloying elements during melting process. Cylindrical samples of diameter $10 \mathrm{~mm}$ x $20 \mathrm{~mm}$ height weighing around 13 gram were prepared, as shown in Fig. 1.

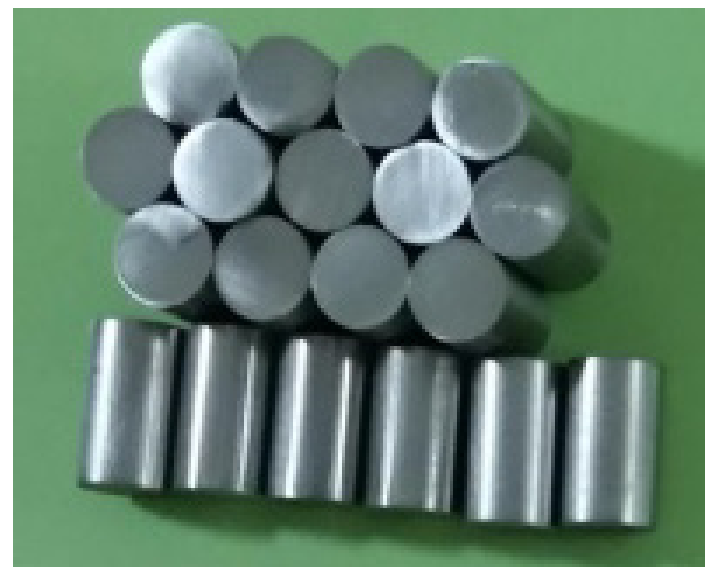

Fig. 1. Cylindrical samples of Ni-Cr-Mo alloy.

\section{Results and Discussions}

Composition was analyzed by X-Ray Fluorescence (XRF) Spectrometer and microstructure was studied by Scanning Electron Microscope. Carbon and sulfur as analyzed by C-S analyzer were below 0.05 wt. $\%$ and 0.006 wt. \% respectively. Beryllium content was analyzed by Inductive Coupled Plasma (ICP) spectroscopy technique. Hardness tested at Vickers Hardness tester. Test results are given in Table 1. Phase transformation temperatures were analyzed by Differential Scanning Calorimetry (DSC); results are given in DTA scans at Fig. 2. Microstructure is shown in Fig. $3 \& 4$. Alloys were tested in dental laboratory to check suitability for dental prostheses.

Table 1. Composition, hardness and melting temperature of prepared Ni-Cr based alloys.

\begin{tabular}{|c|c|c|c|c|c|c|c|c|c|c|c|c|}
\hline \multirow{2}{*}{ Alloy } & & \multicolumn{9}{|c|}{ Composition (wt. \%) } & \multirow{2}{*}{$\begin{array}{l}\text { Hardness, } \\
\text { HV }\end{array}$} & \multirow{2}{*}{$\begin{array}{l}\text { Melting } \\
\text { Temp. } \\
{ }^{\circ} \mathrm{C}\end{array}$} \\
\hline & $\mathrm{Ni}$ & $\mathrm{Cr}$ & Mo & $\mathrm{Al}$ & Co & $\mathrm{Ti}$ & $\mathrm{Be}$ & $\mathrm{Si}$ & $\mathrm{Nb}$ & $\mathrm{Fe}$ & & \\
\hline $\begin{array}{l}\text { Alloy- } \\
\text { A }\end{array}$ & 67.94 & 20.75 & 8.78 & 0.48 & - & - & - & 2.05 & 0.39 & 0.29 & 193 & 1349 \\
\hline $\begin{array}{l}\text { Alloy- } \\
\text { B }\end{array}$ & 74.23 & 14.10 & 5.40 & 2.80 & 0.45 & 0.35 & 1.98 & - & - & 1.40 & 459 & 1163 \\
\hline
\end{tabular}

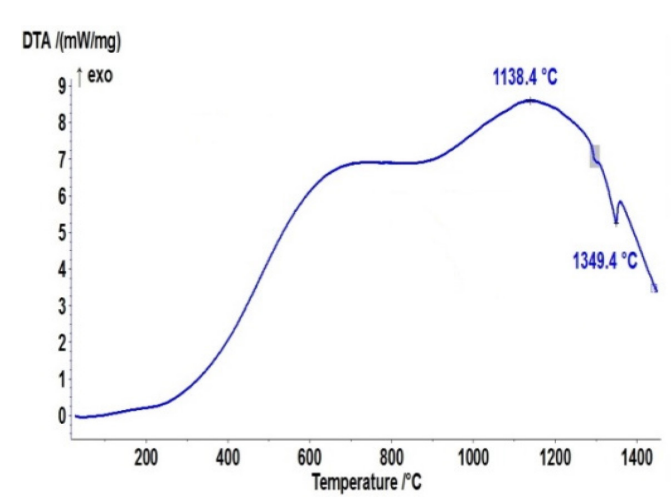

Alloy-A: Be free alloy

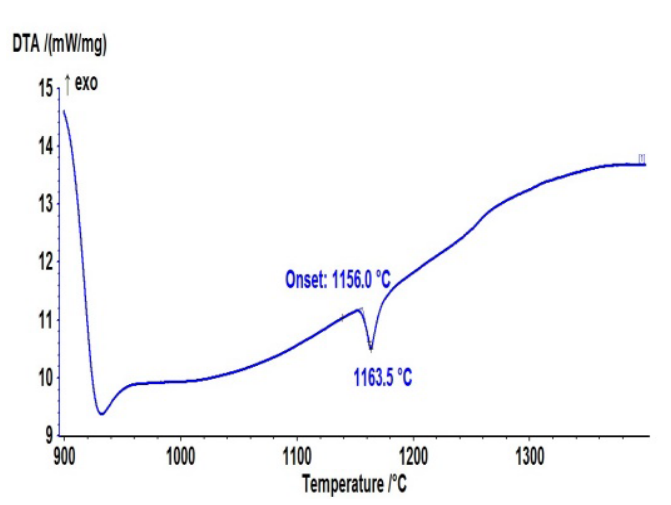

Alloy-B: with Be addition

Fig. 2. DTA scan of Ni-Cr-Mo alloys. 


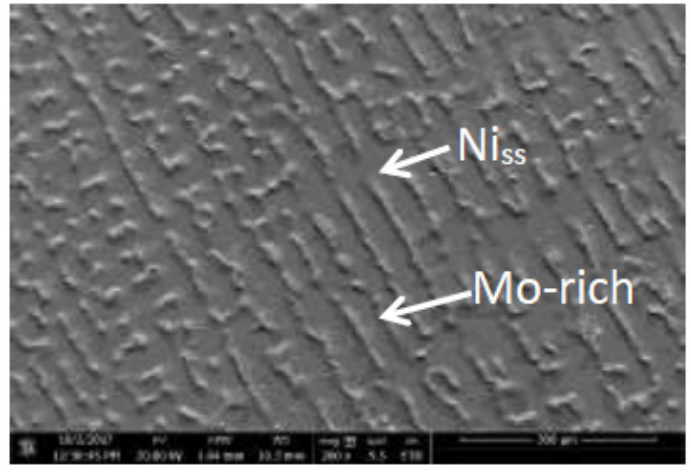

Fig. 3. SEM micrographs showing Nickel Solid Solution $\left(\mathrm{Ni}_{\mathrm{ss}}\right)$ matrix and precipitates rich in Mo at boundaries in Be-free NiCrMo alloy (Alloy-A).

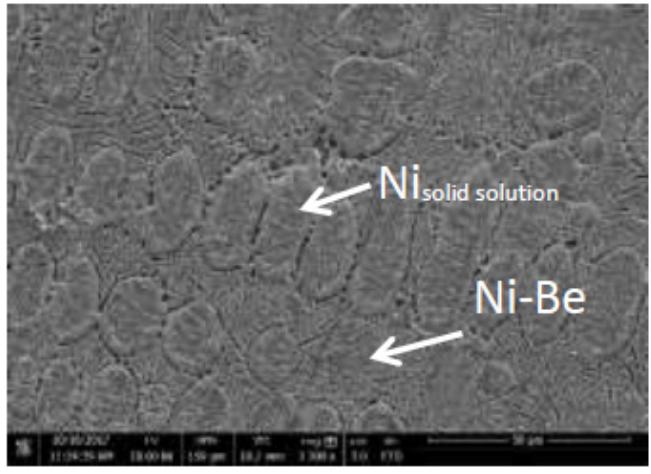

Fig. 4. SEM micrographs shows Ni-Be eutectic phase and $\mathrm{Ni}$ solid solution in $\mathrm{NiCrMoBe}$ alloy (Alloy-B).

Chromium as alloying element is essential for corrosion resistance of the alloy as it improves the passivation of surface [21]. High percentage of chromium forms a continuous layer of $\mathrm{Cr}_{2} \mathrm{O}_{3}$ oxide on the surface, which is hard and adherent to the base metal and thereby protects the metal from further tarnishing.

Microstructure of Be-alloyed sample shows Ni-Be phase which provides better mechanical strength for porcelain bonding with the alloy. Melting temperature of developed Be-alloyed composition is $1163^{\circ} \mathrm{C}$, that helps to have improved castability.

Microstructure of Be-free alloy shows Nickel solid solution with precipitate phases rich in Mo contents at boundaries. Melting temperature of developed Be-free alloy is $1349{ }^{\circ} \mathrm{C}$. Melting temperature of Be-free alloy is higher than that of Be-alloyed sample. Higher melting temperature is due to higher contents of $\mathrm{Cr}$ and Mo. Higher alloying contents of $\mathrm{Mo}$ and $\mathrm{Cr}$ is beneficial for better corrosion resistance. Higher melting point is also beneficial as it gives increased safety margin while porcelain firing [21].

Vickers hardness of Be-free alloy is $193 \mathrm{HV}$, which indicates that the alloy has sufficient mechanical strength and easy for fabrication. Alloys developed are used for dental prostheses and are accepted by dental laboratories.

\section{Conclusion}

Ni-Cr-Mo-Be alloy developed has melting temperature of $1163{ }^{\circ} \mathrm{C}$ and Vickers hardness of $459 \mathrm{HV}$. Be-free NiCrMo alloy developed has melting temperature of $1348^{\circ} \mathrm{C}$ and Vickers hardness of $193 \mathrm{HV}$. Each of the alloys has its own benefits; i.e. Be-added alloy is easy to melt and possess higher hardness, while Be-free alloy is easy for processing due to lower hardness and more flexibility.

\section{Acknowledgement}

Acknowledgement is made to Pakistan Science Foundation for grant for the research work.

\section{References}

[1] H. Knosp, R.J. Holliday, and C.W. Corti, Gold in dentistry: alloys, uses and performance, Gold Bull., 36 (2003) 93-102.

[2] S.M. Paulino, M.B. Leal, V.O. Pagnano, and O.L. Bezzon, The castability of pure titanium compared with Ni-Cr and Ni-Cr-Be alloys, J. Prosthet. Dent., 98 (2007) 445-454.

[3] G.N. Flint, A metallurgical approach to metal contact dermatitis, Cont. Dermat., 39 (1998) 213218. 
[4] R. Galo, R.F. Ribeiro, R.C.S. Rodrigues, L.A. Rocha, and M.da G.C.de Mattos, Effects of chemical composition on the corrosion of dental alloys, Braz. Dent. J., 23 (2012) 141-148.

[5] P. Liliana, S. C. Elena, C.L. Virgil, D.M. Laurentiu and P.S. Daniel, Corrosion behavior of NiCr dental casting alloys, Int. J. Electrochem. Sci., 13 (2018) 410-423.

[6] R.W. Wassell, A.W.G. Walls, and J. G. Steele, Crowns and extra-coronal restorations: materials selection, Br. Dent. J., 192 (2002) 199-211.

[7] J. Bauer, J.F. Costa, C.N. Carvalho, R.H.M. Grande, A.D. Loguercio, and A. Reis, Characterization of two Ni-Cr dental alloys and the influence of casting mode on mechanical properties, J. Prosthodont. Res., 56 (2012) 264-271.

[8] P. Bartolo et al., Biomedical production of implants by additive electro-chemical and physical processes, CIRP Ann.-Manuf. Technol., 61 (2012) 635-655.

[9] J. Palaskar, D.V. Nadgir, and I. Shah, Effect of recasting of nickel: chromium alloy on its castability, J. Indian Prosthodont. Soc., 10 (2010) 160-164.

[10] H.W. Roberts, D.W. Berzins, B.K. Moore, and D.G. Charlton, Metal-Ceramic Alloys in Dentistry: A Review, J. Prosthodont., 18 (2009) 188-194.

[11] R.P.O'Connor, J. R. Mackert, M. L. Myers, and E. E. Parry, Castability, opaque masking, and porcelain bonding of porcelain-fused-to-metal alloys, J. Prosthet. Dent., 75 (1996) 367-374.

[12] O.L. Bezzon, R. F. Ribeiro, J. M. Rollo, and S. Crosara, Castability and resistance of ceramometal bonding in Ni-Cr and Ni-Cr-Be alloys, J. Prosthet. Dent., 85 (2001) 299-301.

[13] Eutectic of Nickel-Beryllium - Google Search. [Online]. Available:

https://www.google.com.pk/search?q=Ni-

Be+eutectic\&espv $=2 \&$ source $=\operatorname{lnms} \& s a=X \& v e d=0 a h U K E w j P 96 y A 4 p z$

TAhVLChoKHYY0DQMQ_AUIBygA\&biw $=1038 \& \mathrm{bih}=470 \& \mathrm{dpr}=1.25 \# \mathrm{q}=$ Eutectic + of $+\mathrm{Nicke}$ 1-Beryllium. [Accessed: 11-Apr-2017].

[14] O.L. Bezzon, M. da G. de Mattos, R. F. Ribeiro, and J. M. de Almeida Rollo, Effect of beryllium on the castability and resistance of ceramometal bonds in nickel-chromium alloys, J. Prosthet. Dent., 80 (1998) 570-574.

[15] P.J. Brockhurst, V.G. McLaverty, and Z. Kasloff, A castability standard for alloys used in restorative dentistry, Oper. Dent., 8 (1983) 130-135.

[16] T.-I. Chai and R.S. Stein, Porosity and accuracy of multiple-unit titanium castings, J. Prosthet. Dent., 73 (1995) 534-541.

[17] C. Bessing, Evaluation of the castability of four different alternative alloys by measuring the marginal sharpness, Acta Odontol. Scand., 44 (1986) 165-172.

[18] D. Chan, V. Guillory, R. Blackman, and K. Chung, The effects of sprue design on the roughness and porosity of titanium castings, J. Prosthet. Dent., 78 (1997) 400-404.

[19] L. J. da Silva et al., Effect of casting atmosphere on the marginal deficiency and misfit of NiCr alloys with and without beryllium, J. Prosthet. Dent., 12 (2016) 127-132.

[20] J. Augustyn-Nadzieja, A. Lukaszczyk, J. Loch., Effect of remelting of the Ni-22Cr-9Mo alloy on its microstructural and electrochemical properties, Arch. Metall. Mater., 62 (2017) 411-418.

[21] L.L. Sousa, J.W.J Silva et al., Corrosion process development of a Ni-Cr-Mo alloy used in dental prosthesis, Intl. J. Eng. Research. Develop., 10 (2014) 70-76. 